\title{
Some Aspects of Protozoan Infections in Immunocompromised Patients - A Review
}

\author{
Marcelo Simão Ferreira/ ${ }^{+}$, Aércio Sebastião Borges
}

\author{
Disciplina de Doenças Infecciosas e Parasitárias, Faculdade de Medicina, Universidade Federal de Uberlândia, Rua Goiás 480, \\ 38400-027 Uberlândia, MG, Brasil
}

\begin{abstract}
Protozoa are among the most important pathogens that can cause infections in immunocompromised hosts. These microorganisms particularly infect individuals with impaired cellular immunity, such as those with hematological neoplasias, renal or heart transplant patients, patients using high doses of corticosteroids, and patients with acquired immunodeficiency syndrome. The protozoa that most frequently cause disease in immunocompromised patients are Toxoplasma gondii, Trypanosoma cruzi, different Leishmania species, and Cryptosporidium parvum; the first two species cause severe acute meningoencephalitis and acute myocarditis, Leishmania sp. causes mucocutaneous or visceral disease, and Cryptosporidium can lead to chronic diarrhea with hepatobiliary involvement. Various serological, parasitological, histological and molecular methods for the diagnosis of these infections are currently available and early institution of specific therapy for each of these organisms is a basic measure to reduce the morbidity and mortality associated with these infections.
\end{abstract}

Key words: protozoa - acquired immunodeficiency syndrome-Aids - opportunistic infections

Since the sixties, opportunistic infections, which frequently occur in patients under some kind of immunosuppression, have become very common in daily clinical practice. The number of immunosuppressed patients susceptible to different infectious or neoplastic processes has increased each decade and culminated in the advent of the acquired immunodeficiency syndrome (Aids) at the beginning of the eighties. The increasing use of transplants (kidney, bone marrow, liver, heart, etc.) and the appearance of new immunosuppressive drugs, nowadays extensively used in these patients as well as in patients with neoplasias and autoimmune diseases, has led to the occurrence of a large number of individuals with chronic immunosuppression in our community, who in turn are predisposed to developing opportunistic infections. Tens of pathogens have been described as etiologic agents of these infections, including viruses, bacteria, protozoa, fungi, and helminths. Immunosuppression, either at the humoral or cellular level, may have different consequences for the host depending on its magnitude, including facilitation of the occurrence of these infections, an increased disease/infection rate, alterations in the clinical manifestation of the infection or exacerbation of its course, among others (Young 1981). Aids and lymphoproliferative neoplasias are examples of conditions that lead to abnormalities in practically all compartments of the immune system; however, T lymphocyte-mediated immune defects predominate. The therapy to which these individuals are submitted (e.g., corticosteroids) and malnutrition caused by the base disease itself represent important cofactors in the predisposition to developing infections. Humoral

${ }^{+}$Corresponding author. Fax: $+55-34-3236.3151$. E-mail: mferreira@nanet.com.br

Received 20 March 2002

Accepted 22 April 2002 immunity defects (hypogammaglobulinemia) and neutropenia (number of serum neutrophils $<1000 / \mathrm{mm}^{3}$ ) usually predispose to the occurrence of bacterial infections caused by Gram-positive cocci, Gram-negative bacilli and some fungi (Candida, Aspergillus), while infections caused by intracellularly multiplying agents such as mycobacteria, endemic mycosis-inducing fungi and protozoa are rare. These last pathogens are frequent agents of infectious processes that occur in Aids or Hodgkin's disease, where the basic defect is the result of cellular immune depression (Karp \& Neva 1999). Aids produces the most severe form of immunosuppression known, and more than one hundred microorganisms causing opportunistic infections in these patients have been identified, many of them intracellular protozoa, which will be discussed in the present review. Infection with human immunodeficiency virus (HIV) leads to important alterations in the clinical course of many disorders caused by these intracellular organisms; curiously, no significant effects of retrovirus-induced immunosuppression on the course of disease have been observed for some protozooses such as malaria. On the other hand, there is evidence that these infections can accelerate the course of HIV infection due to the capacity of many of these organisms to stimulate Th2 type cytokines (IL-4, IL-10, etc.), which favor the progression of the disease caused by HIV (Morrow et al. 1989, Actor et al. 1993, Gilks 1993).

The most frequent protozoan causing opportunistic infections in immunocompromised individuals is Toxoplasma gondii. Its association with severe manifestations of immunosuppression has been known for several decades, and the occurrence of encephalitis, myocarditis and disseminated disease has since then been observed in different clinical conditions such as lymphoreticular neoplasias, solid organ transplantation, and, at present, mainly in patients with Aids. Before the advent of this viral infection, opportunistic infections caused by this and other protozoa had rarely been observed in 
immunocompromised patients. Other coccidia such as Isospora belli and Cryptosporidium parvum only gained clinical importance after the recognition of Aids at the beginning of the eighties. Few cases of reactivated Chagas disease in immunosuppressed patients have been reported in the sixties and seventies, but Trypanosoma cruzi was never considered to be a true opportunistic agent. The same was the case for protozoa of the genus Leishmania whose association with immunosuppressive diseases represented a scientific curiosity in past decades. This panorama changed after the Aids epidemic, and T. cruzi, and especially Leishmania species, are currently gaining great importance as agents of severe opportunistic diseases in patients affected by this retroviral infection. The advances made during the last few years in the chemotherapy of neoplasias, in the use of transplants and in the therapy of autoimmune diseases have led to the reactivation of protozooses under these conditions, thus confirming the opportunistic character of these pathogens (Ferreira et al. 1997, Borges et al. 1999, Ferreira 1999, Rosenthal et al. 2000, Morgado et al. 2000).

The objective of this review was to update and comment upon some aspects of diseases caused by protozoa in immunosuppressed patients. Four parasites which are important causative agents of severe disease in these individuals were chosen, and within this context, we basically focus on pathogenic, clinical, diagnostic and therapeutic aspects of the infections caused by $T$. gondii, $T$. cruzi, Leishmania sp. and C. parvum.

\section{OPPORTUNISTIC DISEASE CAUSED BY TOXOPLASMA GONDII}

About $50 \%$ of the world population is infected with $T$. gondii, a protozoan of the coccidian family, an obligate intracellular parasite that multiplies in any nucleated cell of the vertebrate host and that shows universal distribution (Cesbron-Delauw 1994). Felines are the definitive host, with the domestic cat being the most important. This protozoan is found in nature in three forms: the tachyzoite or intracellular proliferative form, present during the acute phase of infection; tissue cysts, responsible for the latent infection of multiple organs and important in disease transmission, and oocysts found only in felines and eliminated in their feces, with this form representing the source of infection for susceptible hosts (Krick \& Remington 1978). Human infection occurs through the ingestion of cysts in raw or uncooked meat, mainly pork and beef, ingestion of mature oocysts in food or water contaminated with cat feces, or through transplacental passage of the parasite from the mother to the fetus, with acute infection of the latter (Frenkel 1973). Transmission through blood transfusion, laboratory accidents, and organ transplantation is less common, and epidemiological evidence exists indicating hematophagous insects as biological vectors of Toxoplasma (Amato Neto 1970, Herwaldt \& Juranek 1993, Amendoeira 1995).

Toxoplasmosis represents an important public health problem, considering that 0.25 to 5 cases of congenital infection occur per 1,000 livebirths, that approximately 10 to $20 \%$ of uveitis cases are caused by this parasite, and that the prevalence of $T$. gondii-induced encephalitis can reach up to $40 \%$ in patients with Aids (Krick \& Remington 1978, Luft \& Remington 1988). Therefore, toxoplasmosis is of great clinical importance in man in two major situations: as a cause of congenital infection, with 5 to $24 \%$ of children becoming ill and dying during the neonatal period, in addition to the high rate of children with severe neurological and visual sequelae who require education and special and costly care (Frenkel 1973), and as an opportunistic infection of high mortality in immunosuppressed individuals (Carey et al. 1973, Ambroise-Thomas \& Pelloux 1993).

In immunocompetent hosts, the infection is frequently benign, with parasitemia being self-limited, resulting in an asymptomatic clinical form of the disease in most cases. However, in about $20 \%$ of cases acute infection is accompanied by febrile lymphadenopathy, asthenia and lymphomonocytosis, with the course of infection being self-limited (Feldman 1968, Darcy \& Santouro 1994). After this period, T. gondii remains viable in the form of tissue cysts, which reproduce slowly throughout the life of the host, thus characterizing the chronic phase of infection. During this phase, the tissue cysts are controlled by the humoral and cellular immune system, involving T lymphocytes and macrophages which are continuously stimulated by parasite antigens, a fact that protects against reinfection. As a result, parasite multiplication is more active and persists for longer periods of time in less immunologically active tissues such as the central nervous system (CNS) (Johnson 1981, Sims \& Talbot 1989, Darcy $\&$ Santoro 1994).

Immunocompromised hosts, especially those with deficient cellular immunity, are at risk of recrudescence of the chronic infection and dissemination, with the occurrence of fulminating disease. The preferential reactivation of $T$. gondii in the CNS has been demonstrated clinically and experimentally (Van Thiel 1966, Frenkel et al. 1975, Ruskin \& Remington 1976). This fact is probably due to low local immunity, as well as to the presence of the blood-brain barrier which impairs the flow of substances such as specific antibodies and interferon- $\gamma$ (IFN$\gamma)$ that would inhibit parasite multiplication (AmbroiseThomas \& Pelloux 1993). After the CNS, the heart and lungs are the most frequently affected organs (Frenkel 1957, Tschirhart \& Klatt 1988, Jautzke et al. 1993).

After the occurrence of Aids, toxoplasmosis became the most common cause of encephalitis in the United States (Luft \& Remington 1988). Until then, this protozoosis was only sporadically observed in patients with neoplasias, collagen disease or transplant recipients under immunosuppressive therapy. In these patients, the disease resulted in the reactivation of chronic infection, although cases of acute infection, including patients with disseminated disease, have been described for previously seronegative organ recipients whose donors presented serological evidence of a past infection (Frenkel et al. 1975, Luft et al. 1983, Gray et al. 1989, Bertoli et al. 1995).

The clinical presentation of toxoplasmosis ranges from asymptomatic reactivation, commonly observed in previously infected organ recipients and demonstrable by increased post-transplant antibody titers, to severe disseminated disease. The disease manifests as diffuse encephali- 
tis, meningoencephalitis or, more common, tumor lesions with a mass effect. Motor syndrome, consciousness disturbances, seizures and focal signs are common manifestations that are clinically indistinguishable from other CNS complications such as reactivated Chagas disease, primary CNS lymphoma, viral or fungal encephalitis, neurotuberculosis and others, diseases also frequently observed among these patients (Hakes \& Armstrong 1983, Luft \& Remington 1988, Ferreira et al. 1997).

The variety of immune system defects found in individuals with Aids, such as CD4+ T lymphocyte deficiency, reduced activity of cytotoxic T and NK cells, and the low production of immunoregulatory lymphokines such as IFN$\gamma$, may explain the high frequency of reactivated $T$. gondii infection (Fauci 1984).

The new impact of $T$. gondii infection on public health has raised great interest in the understanding of its immunopathogenesis. The infection triggers both humoral and cellular immune responses, with the latter being more important for the development of protective and persistent immunity (Darcy \& Santoro 1994). The role of humoral immunity has been extensively studied. It is known that $T$. gondii infection produces IgM, IgA, IgE and IgG class antibodies, with the first three being detected early during the course of infection. IgM class antibodies are the first to occur and can be detected 7 to 15 days after infection, with maximal concentrations being observed during the second month, followed by a progressive decline and disappearance of these antibodies within a few months. However, low antibody titers may persist for a prolonged period of time, i.e., months or years. IgA antibodies can be detected after the first month of infection in about $95 \%$ of cases, reaching a peak concentration between the second and third months, followed by a decline, which, in most cases, is observed between the fourth and seventh month before the decrease in IgM antibodies. IgA antibody detection is therefore of great diagnostic value in acute toxoplasmosis, since these antibodies are rarely found during the chronic phase of infection (Huskinson et al. 1990, Gross et al. 1992).

Cellular immunity seems to be the main mechanism of defense in the control of toxoplasmosis (Johnson 1981). The role of T lymphocytes in T. gondii infection was first emphasized by Frenkel in 1957. In 1988, the same author observed that athymic rats do not develop protective immunity and that depletion of CD4+ cells eliminates any previously acquired protection (Frenkel 1988). Since then, a series of experimental studies have demonstrated the importance of CD4+ and CD8+ T lymphocytes, which act synergistically, in the control of this disease and in the prevention of its reactivation (Araujo 1991, Gazzinelli et al. 1991, Parker et al. 1991). This group of lymphocytes represents the major source of IFN- $\gamma$, which, in turn, is responsible for resistance during the chronic phase of disease through the activation of macrophages that promote intracellular death of the parasite (Kaufmann 1995). Reactivation of infection is therefore due to a reduction in the expression of IFN- $\gamma$ as well as IFN- $\alpha$, which in turn results in the lack of activation of macrophages and microglial cells (Gazzinelli et al. 1993).

Activated macrophages, NK and LAK cells, and the production of different cytokines, such as IL-2, IL-12 and
IFN- $\gamma$, are of crucial importance for the immune response against $T$. gondii both during the acute and chronic phase of the disease (Gazzinelli et al.1992, 1994).

The diagnosis of acute toxoplasmosis is mainly based on a combination of clinical and laboratory data. In clinical practice, serological tests are routinely employed to detect IgM- and IgG-specific antibodies, including indirect immunofluorescence and immunoenzymatic tests (ELISA), with the latter showing higher sensitivity and specificity (Fuccillo et al. 1987). However, in immunosuppressed patients, particularly those with Aids, the early diagnosis of neurotoxoplasmosis has been limited due to the lack of noninvasive diagnostic tests of high sensitivity and specificity. The clinical picture is nonspecific and cerebrospinal fluid (CSF) findings are found to be normal or show nonspecific alterations such as lymphocytic pleocytosis and discrete CSF hyperproteinorraquia. Imaging analyses such as cranial computed tomography and magnetic resonance are of great value, demonstrating isodense or hypodense, single or multiple lesions with a mass effect, and taking up the contrast dye in a ring-like or nodular manner in more than $90 \%$ of cases. Such findings are highly suggestive of toxoplasmosis reactivation granuloma, but are not pathognomonic (Figueiredo et al. 1983, Wanke et al. 1987, Luft \& Remington 1988). The serological pattern found in these patients is similar to that observed for the general population with inactive infection. Since in basically all cases the disease results in the reactivation of latent and non-acute infection, IgM antibodies are not habitually detected and IgG antibodies do not discriminate between latent and active infection (Luft et al. 1984, Wong et al. 1984, Weiss et al. 1988, Grant et al. 1990), and are even not detectable in a minority of cases with reactivated disease (Zangerle et al. 1991, Porter \& Sande 1992, Garly et al. 1997).

Individuals under immunosuppressive therapy such as organ transplant recipients or patients with malignant diseases, who had been previously infected with $T$. gondii, might show an altered serological profile of this protozoan compatible with reactivation, such as increased IgG antibody titers or, less frequently, increased titers of acute phase antibodies, i.e., IgM, 4 to 13 weeks after the beginning of immunosuppression, and the presence or absence of clinical manifestations, a fact not observed in patients with Aids. On the other hand, seronegative patients receiving organs from seropositive donors may show seroconversion 4 to 6 weeks after transplantation, generally accompanied by disseminated infection whose clinical manifestation usually coincides with the occurrence of antibodies, although late manifestations, i.e., about 10 months after immunosuppressive therapy, have been reported (Luft et al. 1983).

The detection of IgA antibodies has also shown conflicting results. IgA-specific antibodies were detected by immunoblotting in a group of patients with Aids and neurotoxoplasmosis in $91.6 \%$ of serum and CSF samples analyzed (Gross et al. 1992). Brazilian investigators have demonstrated the presence of this antibody in serum in $84 \%$ of 54 patients with this diagnosis (Borges \& Figueiredo 2000a). In contrast, IgA-specific antibodies were detected in sera from HIV-infected patients with and without neurotoxoplasmosis (Darcy et al. 1991). 
In cases of reactivation in the CNS, the detection of anti-Toxoplasma antibodies in CSF should be interpreted with caution, since their presence may only indicate passive passage from serum to the CNS. However, the demonstration of local production of specific antibodies, whose titers were found to be increased in CSF irrespective of a serum increase, has proved to be of diagnostic value in some situations, such as meningoradiculitis caused by Borrelia burgdorferi (Wilske et al. 1986), neurosyphilis (Müller \& Moskophidis 1983), encephalitis caused by herpesvirus and paramyxovirus (Reiber 1980, Felgenhauer 1982), congenital toxoplasmosis (Pinon et al. 1986), and neurotoxoplasmosis itself (Wong et al. 1984, Orefice et al. 1990). In a series of 37 patients with Aids and T. gondii-induced encephalitis, antibodies were detected in CSF in 23 patients. Among 16 patients evaluated, 70\% showed evidence of local production of specific antibodies (Potasman et al. 1988). In another group of patients, indirect immunofluorescence revealed that IgG titers in CSF at a dilution higher than 1/64 show $100 \%$ specificity for the differential diagnosis of neurotoxoplasmosis in Aids. In contrast, $\operatorname{IgA}$ antibodies detected in CSF by ELISA showed $72.7 \%$ specificity. In the same study, the detection of antibody production in the CNS using radial immunodiffusion was not useful for the diagnosis of toxoplasmosis, with a specificity of only $70.8 \%$ (Borges \& Figueiredo 2000b).

Several clinical and experimental studies have reported different results regarding the usefulness of circulating $T$. gondii antigen as a diagnostic marker of acute infection, congenital toxoplasmosis and disease reactivation in immunocompromised patients. However, its value in routine clinical practice is still controversial due to the divergent results obtained with animals models and in human infection (Araujo \& Remington 1980, Dannemann et al. 1991, Fachado et al. 1994, Hafid et al. 1995, Letillois et al. 1995).

Parasite identification in blood through culture media or inoculation into laboratory animals provides questionable sensitivity, the techniques are difficult to carry out and isolation of the parasite is time consuming (Derouin et al. 1987, Tirard et al. 1991, Dannemann et al. 1992).

The use of more sensitive and specific methods, such as the polymerase chain reaction (PCR), has been shown to be effective for the diagnosis of congenital and ocular toxoplasmosis (Dupouy-Camet et al. 1993), but PCR detection of parasitemia in patients with Aids and toxoplasmic encephalitis is only useful in cases of disseminated infection (Khalifa et al. 1994). The usefulness of PCR was also assessed in another study using CSF samples obtained from 14 patients with Aids. Among 9 cases with a diagnosis of neurotoxoplasmosis, PCR was positive in 4 patients only, with no false-positive result being detected (Parmley et al. 1992).

In most cases, the diagnosis of neurotoxoplasmosis is presumptive and based on clinical presentation, tomographic or magnetic resonance findings, and the presence of IgG-specific antibodies in serum. The diagnosis is confirmed based on the therapeutic response which generally occurs between 7 and 14 days (Wanke et al. 1987, Luft et al. 1993). The definitive diagnosis has been made thus far upon demonstration of the parasite, more precisely tachyzoites, in brain tissue obtained by biopsy. However, in addition to being an invasive method which is subject to complications, histopathological analysis confirms the diagnosis in only $50 \%$ of clinically diagnosed cases. Access to the lesion is often impaired or routine staining techniques (Wanke et al. 1987, Cohn et al. 1989), and even immunohistochemistry (Conley \& Jenkins 1981, Hofflin \& Remington 1985), do not detect the parasite in the material obtained. In a histopathological study evaluating a series of 85 cases of neurotoxoplasmosis and Aids, more than 50\% of immunoperoxidase-positive cases were negative when standard techniques were employed (Luft et al. 1984).

In contrast to immunocompetent patients in whom the course of disease is mainly self-limited, toxoplasmosis is fatal in immunosuppressed individuals if not recognized and treated early. The drugs routinely employed in the treatment of toxoplasmosis basically act against the proliferative forms, or tachyzoites, present during the acute phase of infection or during reactivation of latent foci in immunocompromised hosts, but do not eradicate the encysted form of the parasite, the bradyzoites (Israelski \& Remington et al. 1993, Luft et al. 1993). The combination of pyrimethamine and sulfadiazine is considered to be the most effective scheme, with therapy consisting of two phases: attack or acute treatment and maintenance therapy. The regimen of choice is sulfadiazine at the dose of 4 to 6 g/day combined with pyrimethamine at the dose of 50 to $75 \mathrm{mg} /$ day for 4 to 6 weeks. Maintenance therapy consists of a $50 \%$ reduction in the initial dose of both drugs, i.e., $2 \mathrm{~g}$ /day sulfadiazine plus $25 \mathrm{mg}$ /day pyrimethamine throughout immunosuppression, i.e., in the case of patients with Aids, throughout life. A response is observed in 70 to $95 \%$ of cases and $91 \%$ of patients show objective signs of improvement within the first 10 to 14 days (Luft et al. 1993). Clindamycin at the dose of 2.4 to $4.8 \mathrm{~g}$ /day or $100 \mathrm{mg} /$ day dapsone, plus pyrimethamine at the doses reported above, are alternative options for patients who develop sulfa intolerance (Katlama et al. 1996). New macrolides such as clarithromycin $(1.5 \mathrm{~g} / \mathrm{day})$ and azithromycin $(2 \mathrm{~g} /$ day $)$ in combination with pyrimethamine have provided satisfactory results and even demonstrated some action on the cystic form of this protozoan (Saba et al. 1993). The use of clarithromycin plus minocycline and of azithromycin plus sulfadiazine has also been evaluated. A 75\% cure rate was achieved with atovaquone, a hydroxynaphthoquinone acting against cysts and trophozoites, administered at the dose of $3 \mathrm{~g} / \mathrm{day}$, and combination with pyrimethamine may improve this response (Kovacs 1992). Folic acid should be added to sulfa- and pyrimethamine-containing schemes at the dose of 10 to $15 \mathrm{mg} /$ day to prevent the myelosuppression provoked by these drugs.

\section{OPPORTUNISTIC DISEASE CAUSED BY TRYPANOSOMA CRUZI}

Chagas disease still represents one of the most important endemic diseases of the American continent and has been diagnosed from the south of the United States to the south of Argentina, with an estimated number of 16 to 
18 million chagasic patients. In Brazil, 3 to 5 million people are estimated to be infected with $T$. cruzi and, in contrast to what was observed 2 to 3 decades ago, most of these individuals live today at the periphery of large cities as a consequence of the migration of infected individuals of low socioeconomic level from rural areas to urban centers (Pan American Health Organization 1990, Rocha et al. 1994). Even in non-endemic countries such as the United States, more than 100,000 people are estimated to be infected as a result of the massive migration of Latin Americans to this country (Navin et al. 1985).

Since the end of the sixties, several authors have observed the occurrence of severe forms of Chagas disease, notably meningoencephalitis and myocarditis, in patients under severe immunosuppression. Some cases have been described in Brazil (Amato Neto et al. 1968, França et al. 1969, Queiroz 1973), others in Latin-American countries where the parasitosis is endemic (Rivero et al. 1974, Monte Verde et al. 1976, Pizzi et al. 1982), and one case was documented in the United States (Kohl et al. 1982). Usually, severe manifestations of trypanosomiasis that occurs in immunosuppressed patients result in the reactivation of chronic, previously asymptomatic or oligosymptomatic infection, although severe acute forms resulting from blood transfusions have sporadically been reported in the literature (Corona et al. 1988, Wanderley et al. 1988, Grant et al. 1989, Nickersosn et al. 1989). Localized or systemic exuberant clinical manifestations have been observed in patients with lymphoreticular neoplasias, renal, heart and bone marrow transplant patients, and in patients with Aids (Ferreira et al. 1997). Experimental studies conducted on mice and rats chronically infected with $T$. cruzi and submitted to different immunosuppressive drugs have demonstrated reactivation of the disease, accompanied by an increase in parasitemia, aggravation of myocarditis and increased mortality, thus confirming the opportunistic character of this parasite (Brener \& Chiari 1971, McCabe et al. 1985, Sinagra et al. 1993). The use of trypanosomicidal drugs in animals with reactivated infection reduced the magnitude of disease manifestations and prevented further reactivation, findings that are relevant for clinical practice (Meckert et al. 1988).

The understanding of the morphological alterations that occur in immunocompromised chronic chagasic patients has been based on the study of biopsies and autopsy material carried out in a few cases described in the literature. The most frequent anatomopathological finding related to the association between Chagas disease and immunosuppression is acute meningoencephalitis, which is characterized by the presence of generalized cerebral edema and hemorrhagic soft pseudotumoral areas of undefined limits measuring several centimeters; these lesions are generally localized at the brain periphery, affecting the gray and, predominantly, the white substance; lesions can also occur in the brain stem and in the cerebellum. Histologically, the presence of a parenchymatous and perivascular exudate consisting of macrophages, lymphocytes, plasma cells and, more rarely, neutrophils is noted; necrotic foci, hemorrhage and microglial nodules are also commonly found. $T$. cruzi amastigotes are abundant and parasitize glial cells and, rarely, neurons.
Lymphomonocytic meningitis, with the presence of parasites in the meninges, is a constant finding in these cases and permits the in vivo diagnosis upon detection of $T$. cruzi in CSF. Acute myocarditis is another important anatomopathological finding in immunosuppressed chagasic patients, which is characterized by cardiomegaly and focal or diffuse infiltration of the myocardium by mononuclear cells, accompanied by intense parasitism of cardiac fiber cells. Epicarditis and endocarditis can also be observed in these patients. Injury of other organs has been rarely documented; panniculitis might be observed in heart and renal transplant patients in the presence of the parasite; parasitism of the musculature of the esophagus, stomach, colon, ocular globe and uterine cervix has also sporadically been reported (Almeida et al. 1974, Stolf et al. 1987, Oddó et al. 1992, Rocha et al. 1993, 1994).

Few cases of an association between Chagas disease and lymphoreticular neoplasias have been described in the literature, most of them occurring in patients with acute lymphocytic leukemia or Hodgkin's disease. In half these cases, Chagas disease was in fact acute after transfusion and the course of disease was severe since the patients were under marked immunosuppression which was not only the result of the base disease but also of the concomitant use of antineoplastic chemotherapy associated or not with high doses of corticosteroids. The remaining cases were certainly the results of reactivation of chronic infection, since the patients were found to be seropositive upon diagnosis. Among 15 cases selected from the literature, meningoencephalitis was observed in $7 / 15$ cases (46\%), myocarditis in $9 / 15(60 \%)$, and the concomitant occurrence of both manifestation was observed in $3 / 15$ cases $(20 \%)$. The diagnosis was in general confirmed by the presence of parasites in blood, pericardial fluid, or tissue, particularly brain, heart and esophageal tissue. The mortality rate was very high in these cases $(8 / 15,53 \%)$ and survival of the patients directly depended on the early diagnosis and the rapid institution of specific therapy (Ferreira et al. 1997).

Transplants are increasingly being performed in patients with Chagas disease. Many of them receive kidney or heart transplants, the latter for the treatment of dilated myocardiopathy caused by the parasitosis itself. In renal transplantation, two modalities of trypanosomiasis can be discussed: (1) the transmission of T. cruzi from living donors or cadavers to non-chagasic kidney recipients through the transplanted organ itself (therefore, the donor has Chagas disease) or through the transfusion of blood or blood derivatives; (2) reactivation of chronic parasitosis after transplantation as the result of immunosuppression due to the use of corticosteroids, cyclosporin or tacrolimus. In the case of the first modality, the clinical manifestations are similar to those observed during the acute phase of infection and consist of fever, hepatosplenomegaly, myalgias and signs of myocarditis, including the presence of cardiac arrhythmias. The time interval between transplantation and the onset of clinical manifestations can be as short as 30 days or as long as 14 months. In all of these patients, T. cruzi is present in peripheral blood and anti-T. cruzi IgM antibodies are also detectable in serum by indirect immunofluorescence. In 
cases of reactivated chronic infection, involvement of the CNS might be observed in the form of severe meningoencephalitis, which can lead to death in some cases. It is important to note that positive serology for Chagas disease of the organ donor or recipient does not represent a contraindication for transplantation, since long-term follow-up of chagasic transplant recipients has shown that in most patients the disease is not reactivated and that there is no need for prophylactic pre- or post-transplant anti-T. cruzi therapy; this treatment only needs to be initiated if there is evidence of acute or reactivated infection. Treatment of the clinical disease of any modality caused by $T$. cruzi consists of oral benznidazole at the dose of $5 \mathrm{mg} / \mathrm{kg}$ per day (in two doses) for 60 days; alternatively, nifurtimox, currently not available in Brazil, may be used. The anti-parasitic treatment has been shown to be effective in these cases (Jost et al. 1977, Chocair et al. 1985, Figueiredo et al. 1990, Cantarovith et al. 1992, De Arteaga et al. 1992, Lopez Blanco et al. 1992, Luders et al. 1992).

A few patients with chagasic heart disease have already received heart transplants; these individuals were submitted to powerful immunosuppression after transplantation consisting of high doses of corticosteroids, immunosuppressors (azathioprine, cyclosporin, tacrolimus, etc.) and anti-lymphocytic globulin. The combination of these drugs, used to prevent organ rejection, markedly favored reactivation of the protozoosis in at least two thirds of cases. The time between transplantation and reactivation might exceed one year. The predominant clinical manifestations were fever, signs of acute myocarditis accompanied by heart failure and arrhythmias, and infiltrating erythematous cutaneous lesions, which are histologically characterized by panniculitis with the presence of a large number of $T$. cruzi amastigotes. The diagnosis was in general made by anatomopathological examination of endocavitary biopsies. Curiously, no parasites were observed in peripheral blood, even after repeated analyses using different parasitological techniques. Benznidazole administered at the recommended doses for 60 days was found to effective in the treatment of reactivated Chagas disease, leading to the disappearance of signs and symptoms of the disease, but without curing the parasitosis. Allopurinol has shown some efficacy in a small series recently studied in Brazil. The prophylactic pre- or post-transplant use of benznidazole is not indicated since this drug does not eliminate the parasite from the organism and, therefore, does not prevent reactivation (Stolf et al. 1987, Bocchi et al. 1993, Kirchoff 1993).

Only one case of fulminating Chagas disease has been described in the literature in a bone marrow transplant recipient (Geiseler et al. 1987).

The advent of the Aids epidemic at the beginning of the eighties opened the possibility of the occurrence of reactivation of this parasitosis in co-infected individuals under profound immunosuppression as a result of this viral infection.

About 80 cases of reactivation in patients with Aids have been documented in the literature, most of them reported in Brazil and Argentina. Only one tenth of these cases have been described in detail, while the remaining cases have been communicated at congresses or specialty symposia (Ferreira et al. 1997, Rocha et al. 1997, Sartori et al. 1998). Curiously, the first Aids case reported in the United States involved an immigrant from El Salvador who carried both infections (Gluckstein et al. 1992). At the beginning of the nineties, about $6 \%$ of autopsied HIV-positive patients with reactivated Chagas disease had been recorded in our hospital in Uberlândia, MG, an area endemic for Chagas disease (Borges et al. 1996). Although in most published cases no information regarding the CD4 T lymphocyte count is available, recent findings indicate that practically all patients with reactivated disease have CD4 T cell levels below 200 cells $/ \mathrm{mm}^{3}$, similarly to what is observed for other opportunistic infections affecting these patients (Ferreira et al. 1997, Sartori et al. 1998). In contrast to heart transplant patients with reactivated disease in whom myocardial involvement is predominant, involvement of the CNS is common in patients with Aids, being observed in 75 to $80 \%$ of co-infected individuals. CNS involvement manifests as acute, uni- or multifocal meningoencephalitis with fever, headache, vomiting, seizures and focal neurological signs. Analysis of CSF samples demonstrates the presence of mild to moderate pleocytosis $\left(<100\right.$ cells $\left./ \mathrm{mm}^{3}\right)$, predominantly consisting of mononuclear cells, elevated protein levels and the presence of T. cruzi upon direct examination of the fluid (Ferreira et al. 1991, 1997). Parasites are also easily detected in peripheral blood using Giemsa-stained smears, by concentration methods (Strout, microhematocrit, etc.), and even by the quantitative buffy coat (QBC) assay. The identification of parasitemia by other techniques such as blood culture or xenodiagnosis should not be considered as evidence of reactivation, since these methods may yield a positive result during any phase of the disease, including chagasic patients not infected with HIV (Ferreira et al. 1997).

Modern imaging methods are frequently used to diagnose encephalic lesions in HIV-positive patients. In the case of chagasic meningoencephalitis, cranial computed tomography reveals the presence of hypodense, predominantly subcortical, single or multiple lesions which have the shape of a ring after contrast injection. These lesions closely resemble those seen in neurotoxoplasmosis, although the main areas involved in this parasitosis are the base nuclei and the thalamus. Magnetic nuclear resonance seems to be more sensitive than tomography, detecting a larger number of lesions in both infections (Rocha et al. 1994, Ferreira et al. 1997, Ferreira 1999).

Another organ frequently involved in the reactivation of American trypanosomiasis is the heart. The frequency of this occurrence is not known, since no complete autopsy study of cases published in the literature or communicated at congresses exists. Involvement of the heart is often discrete and is certainly not detected clinically or radiologically. Based on the few cases published, about half of the patients are estimated to present myocarditis during disease reactivation. Clinical manifestations, when present, include signs and symptoms of congestive heart failure (dyspnea, tachycardia, edemas, etc.) and the presence of cardiac arrhythmias. An increase in heart volume, together with the presence of sometimes voluminous peri- 
cardial hemorrhage, can be documented by two-dimensional echocardiography. Parasites may be present in the pericardial fluid. In biopsy or autopsy studies, the presence of $T$. cruzi should be always confirmed by immunohistochemical techniques or by electron microscopy due to the simultaneous presence of associated infections (for example, T. gondii) (Ferreira et al. 1997, Sartori et al. 1998).

The diagnosis of Chagas disease reactivation should be made as early as possible, since anti-parasite treatment can improve the prognosis and survival of the patient. The identification of $T$. cruzi in body fluids (blood, CSF, pericardial or ascitic fluid, etc.) is the key to the diagnosis of Chagas disease and should be carried out as soon as a suspicion exists. Brain or myocardial biopsies should also be performed, if possible. Survival of patients with Chagas disease, even when treated, is low, although the latest cases published showed remission a long time after treatment owing to the concomitant administration of antiretroviral drugs that increase and stabilize serum CD4 T lymphocyte levels (Ferreira et al. 1997, Sartori et al. 1998, Ferreira 1999).

The drugs acting on $T$. cruzi are nifurtimox and benznidazole, with only the latter being available in Brazil. Benznidazole is administered orally at the dose of $5 \mathrm{mg} / \mathrm{kg}$ per day in two doses for a period of 60 days. The drug seems to be effective in the treatment of disease reactivation under any type of immunosuppression, including HIVpositive patients. Fever, neurological or cardiac signs, and cutaneous lesions generally regress within the first 2 or 3 weeks of treatment, with no parasitemia being detected upon direct examination, blood culture or xenodiagnosis. Adverse effects commonly occur after the first days of drug use, with cutaneous eruption, peripheral neuropathy and granulocytopenia being the most frequent. In countries where nifurtimox is still commercialized, its use is indicated in situations of reactivation at the dose of 8 to $10 \mathrm{mg} / \mathrm{kg}$ per day, orally, for 60 to 90 days. Its efficacy as a trypanosomicidal drug seems to be similar to that of benznidazole. Triazole derivatives (itraconazole, fluconazole) have been used for reactivation treatment by some authors, with apparent success, although they are not recommended as first-line therapy in these situations (Nishioka et al. 1993, Ferreira et al. 1997, Sartori et al. 1998, Ferreira 1999). After remission and treatment discontinuation, the introduction of a second prophylaxis is recommended, since further reactivations may occur later. An expert committee, brought together by the Pan American Health Organization in 2000, recommended the use of benznidazole at the dose of $5 \mathrm{mg} / \mathrm{kg}$ per day, three times a week, for an undefined period of time as secondary prophylaxis; nifurtimox might also be used for this purpose. Antiretroviral therapy should be systematically administered to these patients in order to maintain elevated CD4 $\mathrm{T}$ lymphocyte levels, thus reducing the chance for disease reactivation. A group of $13 \mathrm{HIV}$-positive chagasic patients under retroviral therapy have been followed up by our group for months and none of them has shown any clinical signs of trypanosomiasis activity thus far. There is currently no consensus regarding the use of drugs as primary prophylaxis in chagasic patients infected with HIV (Anonymous 1996).

\section{OPPORTUNISTIC DISEASE CAUSED BY LEISHMANIA SP.}

Leishmaniasis is a parasitic disease widely distributed throughout the world, which is endemic in the tropical and subtropical regions of 88 countries. About 2 million cases are estimated to occur annually worldwide, most of them presenting the cutaneous or mucosal form. Leishmania is an obligate intracellular parasite and control of this infection involves a vigorous Th1-depdendent cellular immune response. Therefore, the observation of the opportunistic character of this protozoosis during the last few years was no surprise, with this parasite causing mucocutaneous or visceral disease in immunosuppressed patients, particularly those infected with HIV (Alvar et al. 1994, 1997). Co-infection with this retrovirus emerged as a new and interesting pathology, whose frequency is currently increasing. Cases of HIV-Leishmania co-infection have been reported in more than 25 countries, particularly those located at the margins of the Mediterranean Sea such as Portugal, Spain, France, Italy, Greece and NorthAfrican countries, and, to a lesser extent, in Equatorial African, Asian and South American countries (Alvar 1994, Dedet et al. 1995, Gradoni et al. 1996, Borges et al. 1999). More than 2,000 cases of visceral leishmaniasis associated with HIV infection have been reported in European countries alone, a fact due to the simultaneous dissemination of both diseases and the overlapping geographic distribution of the two infections as the result of the urbanization of leishmaniasis and the ruralization of Aids (WHO 1995, Ferreira 1996, Rabelo et al. 1998). In Brazil, about 80 cases of HIV-Leishmania co-infection have been documented, most of them with the mucocutaneous form of the disease and few cases with the visceral form. This number will probably increase during the next few years, since infectologists are currently more aware of the diagnosis of this co-infection (Rabelo et al. 1998, Borges et al. 1999).

Today, it has been demonstrated that Aids and leishmaniasis, particularly the visceral form, can interact in a vicious cycle of mutual aggravation. Aids leads to the dissemination of the parasites to practically all organs and body systems, while, on the other hand, leishmaniasis accelerates the course of HIV infection by decreasing the latent period of viral infection and thus the life expectancy of the patient. Various other opportunistic infections such as tuberculosis or systemic mycoses are found in co-infected patients, demonstrating the marked immunosuppression generated in these individuals (Albrecht 1998, Rosenthal et al. 1999).

The epidemiology of visceral leishmaniasis in the Mediterranean region suffered profound changes since the advent of Aids. It has been known for decades that this infection frequently affects children, but this picture changed radically after the occurrence of Aids, since most cases diagnosed at present in these countries refer to young adults suffering from immunosuppression due to HIV. Leishmaniasis has sporadically been detected in individuals with other types of immunosuppression, such as renal transplant patients and patients with lymphoreticular neoplasias, among others (FernandezGuerrero et al. 1987, Alvar 1994). Most HIV-positive co- 
infected patients are addicted to injectable drugs. Thus, when an individual with leishmaniasis shares syringes and needles used for drug injection with other partners, leishmaniasis might be transmitted through blood remaining on the material, with this fact representing an alternative form of transmission of this protozoosis between individuals. Amastigotes are demonstrable in peripheral blood smears in more than $60 \%$ of co-infected patients, thus confirming the existence of this form of transmission. In addition, these individuals can serve as true reservoirs of the parasite by easily infecting phlebotomine flies feeding on their blood (Medrano et al. 1993, Alvar 1994, Alvar et al. 1997).

Leishmaniasis is currently known to frequently manifest in the form of subclinical infections which can persist in individuals for months or years. Most cases of visceral leishmaniasis that occur in HIV-positive patients are believed to result from reactivation of latent infections, although primary infections with $L$. infantum have been reported among patients in Italy and Spain (Alvar 1994, Gradoni et al. 1996, Alvar et al. 1997).

Any Leishmania species can cause disease in immunocompromised patients. Parasites isolated from co-infected patients included strains previously undetected in immunocompetent individuals, including some species restricted to lower animals. Visceral dissemination of species that commonly cause the cutaneous form of the disease (e.g., L. braziliensis) has also been observed by us and others (Coura et al. 1987, Machado et al. 1992, Alvar et al. 1997).

The clinical-laboratory presentation of simultaneous HIV and Leishmania infections has been described in detail in the literature. Many cases show an asymptomatic or oligosymptomatic course and parasites are casually detected during routine blood and bone marrow examination. Cutaneous forms of the disease with disseminated lesions, involving the nasal, oral or pharyngeal mucosa, have been observed in patients with advanced stage Aids, sometimes accompanied by extensively destructive lesions; lesion recurrence after treatment has been a common event among patients with an apparent therapeutic response to a first course of antimonial drugs or amphotericin B. For the visceral form, classical clinical manifestations include fever, weight loss, hepatosplenomegaly and peripheral pancytopenia, which are observed in about 75 to $80 \%$ of cases; adenopathies and signs of pulmonary involvement with interstitial pneumopathy have also been documented. The gastrointestinal tract is frequently found to be involved (in about $30 \%$ of cases), and amastigotes have been isolated from the esophagus, stomach, small and large bowel, pancreas and, obviously, liver. In these cases no clinical signs and symptoms might be noted, although many patients present abdominal pain, diarrhea, vomiting and dysphagia; biopsies obtained from any part of the digestive tract easily detect the presence of parasites. Hemorrhagic diathesis due to thrombocytopenia and hepatic involvement may occur in a small percentage of cases. Most co-infected patients have low CD4 T lymphocyte counts, usually less than 200 cells/ $\mathrm{mm}^{3}$, a fact that might explain the frequent association with other opportunistic infections commonly observed in these patients, such as esophageal candidiasis, pneumocystosis, tuberculosis, toxoplasmosis, cryptococcosis, and cytomegalovirus infection. Some authors have observed that the clinical presentation of visceral leishmaniasis is influenced by the CD4 T cell count, i.e., the lower the lymphocyte count the more atypical is the clinical picture. Nontypical localization of the disease has been frequently found in patients with CD4 T lymphocyte counts $<50$ cells $/ \mathrm{mm}^{3}$ (La Rosa et al. 2001). The clinical presentation of visceral leishmaniasis itself should be differentiated from other infections, particularly disseminated histoplasmosis and miliary tuberculosis, which present highly overlapping clinical manifestations (Dedet et al. 1995, Rosenthal et al. 1995, 2000, Alvar et al. 1997, Borges et al. 1999).

The diagnosis of leishmaniasis in patients with Aids is easy due to the fact that these individuals present a large number of parasites in their tissues. Detection of Leishmania in bone marrow or spleen aspirates shows high positivity (70 to 100\%), thus permitting a rapid confirmation of the diagnosis; as mentioned above, peripheral blood smears stained with Giemsa can reveal the presence of the parasite in up to $60 \%$ of cases. A recent study employing the $\mathrm{QBC}$ technique, which is widely used for the parasitological diagnosis of malaria, easily demonstrated the presence of the amastigote forms of the parasite in bone marrow and peripheral blood of non-immunosuppressed patients with kala-azar; this method may therefore be of great diagnostic value in co-infected patients (Liarte et al. 2001). Liver biopsies may also serve as a tool to confirm the diagnosis of the parasitosis. Unfortunately, most co-infected patients do not produce sufficient amounts of antibody, and serological tests (ELISA, immunofluorescence) are positive in only 40 to $50 \%$ of cases, thus being of limited value for the diagnosis of this infection. In the mucocutaneous form, biopsy almost always leads to a diagnosis due to the abundance of parasites in the material examined. PCR may be used for the detection of these protozoa in blood and other body fluids, and tissue removed for biopsy (Piarroux et al. 1994).

Treatment of HIV-positive patients co-infected with Leishmania has generally been difficult. Pentavalent antimony, preferentially $\mathrm{N}$-methylglucamine antimonate, is still considered the drug of choice for these patients, with $20 \mathrm{mg} / \mathrm{kg}$ of antimony base being administered intravenously, daily for 30 days. This recommendation is valid for both the mucocutaneous and the visceral form of the disease. In a Spanish study, treatment with antimonial drugs led to remission in most patients, although recurrence was later observed for most cases (Lopes-Velez et al. 1998). On the other hand, French authors only observed a 50\% clinical and parasitological response to antimonial drugs in co-infected patients (Rosenthal et al. 1995). In countries with proven resistance of the parasite to antimonial drugs, such as India, the rates of therapeutic failure and recurrence are probably much higher. An increased rate of side effects upon the use of these drugs has been observed for HIV-positive patients; myocardiotoxicity and elevated serum amylase levels due to pancreatitis have been reported by several authors (Alvar et al. 1997, Lopez-Velez et al. 1998). 
Within this context, amphotericin B probably represents a more efficient therapy for all forms of leishmaniasis in HIV-positive patients. In the south of France, practically $100 \%$ of patients with visceral disease responded to an initial course of amphotericin B (Rosenthal et al. 1995). Total amphotericin B doses of about 1 to $2 \mathrm{~g}$ were sufficient to induce remission in most cases. Liposomal amphotericin B used in these patients initially showed surprisingly good results, although it did not prevent disease recurrence. Unfortunately, its high cost limits its use in Brazil (Lopez-Velez et al. 1998). Classical side effects have been observed with the use of amphotericin B (fever, shivering, hypopotassemia, nephrotoxicity, etc.), with these effects being less frequent when lipid formulations are used, which also permit the use of higher doses (3-4 g/ total dose). Pentamidine, allopurinol and paromomycin are other drugs used for the treatment of co-infected patients, although the results are not promising. The use of recombinant IFN- $\gamma$ in combination with antimonial drugs showed a good response in three Spanish cases of kala-azar associated with HIV infection (De Gorgolas et al. 1993).

Irrespective of the type of drug used for the treatment of this clinical entity, there is a clear tendency towards multiple recurrences after the initial therapeutic course (30\% after 6 months and 60-70\% after 12 months) (LopezVelez et al. 1998). Based on this observation, several authors have recommended long-term secondary prophylaxis as done for other opportunistic infections in patients with Aids. Pentavalent antimony administered once a month seems to be efficient in preventing recurrence in these patients (Ribera et al. 1996). Pentamidine has also been used for this purpose, with the advantage of simultaneously acting on Pneumocystis carinii (Lopez-Velez et al. 1998). Amphotericin B deoxycholate and lipid formulations may be employed for prophylaxis at weekly doses, particularly in patients who previously developed systemic mycoses that require long-term maintenance therapy to prevent recurrence (Davidson \& Russo 1994).

With respect to the mortality of co-infected individuals, about $20 \%$ of patients die during the first episode of visceral disease and about $70 \%$ die after one year, during which the disease relapsed one or more times. Factors leading to a poor prognosis include advanced immunosuppression (very low CD4 levels) and thrombocytopenia (Lopez-Velez et al. 1998). The introduction of combined antiretroviral therapy in order to improve the immunological parameters leads to a reduction in the number of reactivation episodes and subsequent recurrences in the case of both the visceral and the mucocutaneous forms of the disease (La Rosa et al. 2001).

\section{OPPORTUNISTIC DISEASE CAUSED BY CRYPTOSPORI- DIUM PARVUM}

Over the last few years, there has been growing interest on the part of doctors and parasitologists in human intestinal coccidia, which can cause disease in both immunocompetent and immunocompromised individuals. Three of these protozoa have been the subject of numerous publications, not only as true opportunistic agents of diseases that occur in immunosuppressed patients but also as the etiologic agent of large epidemics generally associated with contaminated water or food. C. parvum, I. belli and Cyclospora cayetanensis are the main coccidian parasites found in the digestive tract of mammals, including humans. I. belli rarely causes infection in immunocompetent individuals but is one of the main causes of diarrhea in patients with Aids. In contrast, $C$. cayetanensis, discovered only some years ago, has been responsible for large epidemics in different countries worldwide, causing prolonged diarrhea in immunocompetent and -suppressed individuals. In the present review we only focus on some aspects of human cryptosporidiosis (Fayer \& Ungar 1986, Guerrant 1997, Griffiths 1998).

C. parvum was described for the first at the beginning of the 20th century in the digestive tract of the common mouse. However, its pathogenic role in animals was only recognized many decades later, during the seventies, when it was shown to be an important agent of enteritis in cows and fowl (turkeys). The first human cases were described in 1976, but the disease only gained importance after the occurrence of Aids in 1982. Despite its opportunistic behavior in these patients, $C$. parvum is also known to be an important cause of acute gastroenteritis in immunocompetent individuals (Fayer \& Ungar 1986). The evolutive cycle of this parasite is completed within a single host; infection starts with the ingestion of water or food contaminated with oocysts eliminated in the feces of infected individuals or animals. The oocysts, measuring on average $5 \mu \mathrm{m}$, contain 4 infectious sporozoites. Upon release into the intestinal lumen, the sporozoites penetrate intestinal cells, where they mature asexually inside extracytoplasmic superficial parasitophorous vacuoles into type 1 meronts, which, in turn, release merozoites that again invade enterocytes, generating a cycle of type 2 meronts (type 2 merogony), thus representing a cycle of internal autoinfection. However, some second generation merozoites may differentiate into macro- and microgametocytes which are fertilized and produce the egg or zygote after a period of maturation. This zygote transforms into an oocyst which divides by sporogony, resulting in the production of sporozoites. Millions of mature oocysts are eliminated in feces, thus leading to broad contamination of the environment where they remain viable for many months (Fayer \& Ungar 1986, Guerrant 1997, Griffiths 1998).

Cryptosporidiosis is found worldwide, with the highest prevalence being observed in less developed countries, mainly Latin America and Africa. Seroprevalence studies have shown a positivity rate of the order of $30 \%$ in North America and Europe, and of up to 60\% in LatinAmerican countries. The most affected population groups are children aged less than two years and immunocompromised individuals, particularly those with Aids. The prevalence rate varies among these individuals according to the geographical regions studied, with rates ranging from 2-4\% in the United States to 50\% in Africa. Two Brazilian studies, one carried out in Rio de Janeiro and the other in Uberlândia, MG, found rates of infection with this protozoan of 18.2 and $13 \%$, respectively, considering that all individuals met the criteria for the diagnosis of Aids. Patients with other types of immunosuppression, such as congenital hypogammaglobulinemia, protein-calo- 
rie malnutrition, diabetes mellitus and hematological neoplasias, show a high predisposition to developing severe forms of cryptosporidiosis (Moura et al. 1989, Costa-Cruz \& Ferreira 1996, Pedersen et al. 1996, Sorvillo et al. 1998).

The main route of transmission of cryptosporidiosis is through the ingestion of water or food contaminated with mature oocysts, with the ingestion of only 10 oocysts being sufficient to produce infection, and with the parasitosis persisting due to the cycle of internal autoinfection (Fayer \& Ungar 1986). Thousands of people have been infected in urban epidemics that occurred in England and in the United States due to contamination of the water sources with fecal material containing oocysts, which are resistant to the usual chlorination of drinkable water sources available to the population. Smaller outbreaks were observed in day-care centers, hospitals and rural areas, where contact with contaminated animals is common (Richardson et al. 1991, Moore et al. 1993, Goldstein 1996, Hoxie et al. 1997).

The clinical manifestations of cryptosporidiosis vary according to the host's immunological status. Symptomatic or oligosymptomatic infections are common in endemic areas and can be identified through serological population surveys (Fayer \& Ungar 1986, Guerrant 1997). The most common clinical form of this protozoosis in immunocompetent individuals is acute gastroenteritis; this modality of the disease is self-limited and the incubation period ranges from 1 to 2 weeks. The patient in general presents with low fever, colic abdominal pain, headache, loss of appetite, nausea, vomiting and diarrhea, which is secretory and disabsorptive leading to the loss of various liters of fluid per day. The duration of the clinical manifestations ranges from 3 to 12 days in most cases, although in some it may persist for more than 4 weeks. Clinical cure does not coincide with parasitological cure, since oocyst elimination can last for several weeks (Fayer \& Ungar 1986, Cardell \& Adiss 1994).

In immunosuppressed patients, including patients with Aids, the clinical presentation of this protozoosis is severe and consists of intense diarrhea, with several daily bowel movements, accompanied by voluminous loss of fluid, dehydration and marked weight loss. These manifestations last for several weeks, and cryptosporidiosis can be considered incurable in HIV-infected patients in the advanced phase of the disease (Pozio et al. 1997, Griffiths 1998, Manabe et al. 1998).

Similar to other opportunistic infections that occur in HIV-infected patients, severe cryptosporidiosis also tends to affect patients with low CD4 T lymphocyte levels (below 100 cells $/ \mathrm{mm}^{3}$ ) (Flanigan et al. 1992). Extraintestinal manifestations of this coccidiosis are also observed in patients with Aids, and particularly affect the biliary tract, liver, pancreas, joints and the respiratory system. Biliary tract infections include alithiasic cholecystitis, sclerosing cholangitis, papillitis and terminal bile duct stenosis (Bonacini 1992, Manabe et al. 1998, Griffiths 1998).

The digestive presentation of cryptosporidiosis should be differentiated from other causes of acute gastroenteritis in immunocompetent individuals, such as infections caused by bacteria (Escherichia coli, Cam- pylobacter, Salmonella sp., etc.), viruses (rotavirus) and other protozoa (Giardia lamblia, I. belli and $C$. cayetanensis). In patients with Aids, the differential diagnosis should also be made with isosporiasis and cyclosporiasis, with diarrhea caused by microsporidia (Enterocytozoon bieneusi, Encephalitozoon intestinalis), and with chronic diarrhea induced by HIV itself (Griffiths 1998).

The most practical and easiest way of diagnosing cryptosporidiosis is the detection of parasite oocysts in feces or other body fluids. Various techniques have been used to visualize these oocysts, such as Ziehl-Neelsen staining, modified, Kinyoun carbolfuchsin staining, modified, and staining with safranin-methylene blue and methenamine silver. Concentration methods, such as formalinether sedimentation or Sheather's sugar flotation method, increase considerably the sensitivity of oocyst detection. The oocysts of this protozoon can be visualized in histological sections of intestinal mucosa obtained by biopsy and stained with hematoxylin-eosin as single cells or grouped on the mucosal surface, i.e., at the brush border of the intestinal epithelium. More recent techniques using fluorescent dyes such as acridine orange and auramine carbolfuchsin provided results comparable to those obtained with the staining methods described above for diarrheic feces, and are able to detect parasites even in formed feces. Immunoenzymatic techniques (ELISA) using monoclonal antibodies have shown a high degree of sensitivity and specificity for the detection of oocysts in feces and contaminated water (Costa-Cruz et al. 1996, Hoxie et al. 1997, Guerrant 1997, Griffiths 1998). Serological tests for the detection of antibodies represent an alternative to parasitological methods for the diagnosis of cryptosporidiosis. Immunoenzymatic assays (ELISA) using crude extract of ruptured oocysts as antigen have shown good sensitivity, although some studies have demonstrated that immunoblotting is much more sensitive and specific for antibody detection. In these cases, IgA type responses are observed which are directed against antigens found on the surface of sporozoites, the infectious form of the parasite; such antibodies seem to exert a protective effect against symptomatic infection (Mooss et al. 1998, Eisemberg et al. 2001). A specific PCR has been developed and may represent a better option for the diagnosis of this infection in the future (Griffiths 1998).

The disease is self-limited in immunocompetent patients who do not require specific treatment in addition to hydration and adequate water-electrolyte replacement. In patients with Aids, hydration should be vigorous, particularly in cases with the severe and debilitating form of the disease. Antidiarrheal agents such as diphenoxylate and loperamide should be used to reduce the loss of water through feces and the number of evacuations, thus improving the quality of life of these patients. A somatostatin analog, octreotide acetate, inhibits intestinal secretion of fluids and improves diarrhea in these patients, but, obviously, without a parasitological cure (Cello et al. 1991). Various drugs have been tested for the treatment of cryptosporidiosis, but none of them has shown a complete curative effect thus far. The orally administered macrolides spiramycin, roxithromycin and azithromycin 
have demonstrated partial efficacy, but without eradication of the parasite in most of the individuals treated (Soave et al 1990). Paromomycin, an aminoglycoside administered orally at the dose of $2 \mathrm{~g} / \mathrm{day}$, has shown good activity on this coccidium. In some series, symptomatic improvement was observed in most patients and eradication of the infection was even reported in a few individuals (Clezy et al 1991, Fichtembaun et al. 1993). However, a recent controlled study did not demonstrate the expected efficacy of this drug in the treatment of human cryptosporidiosis (Hewitt et al. 2000).

Since patients with cryptosporidiosis eliminate large amounts of oocysts in their feces, they might easily contaminate the environment, the persons in contact with them, water and food. Universal precautions, such as washing the hands and adequate destination of dejecta and contaminated material, are fundamental for the prevention of this protozoosis and epidemic outbreaks. However, in the case of a cryptosporidiosis outbreak, particularly that transmitted through contaminated water reservoirs, the population should be advised to consume only boiled or bottled water, a recommendation that should be also made to patients with Aids. It is important to remember that chlorination does not eliminate Cryptosporidium oocysts from the public water reservoirs, which eventually become contaminated through the feces of domestic animals present in nearby rural areas (Hayes et al. 1989, Moore et al. 1993).

\section{REFERENCES}

Actor JK, Shiarai M, Kullberg MC, Buller RM, Sher A, Berzojsky JA 1993. Helminth infection results in decreased virus-specific CD8 + cytotoxic T cell and Th1 cytokine responses as well as delayed virus clearence. Proc Natl Acad Sci USA 90: 948-952.

Albrecht H 1998. Leishmaniasis: new perspectives on an underappreciated opportunistic infection. AIDS 12: 22252226.

Almeida, EA Engelman, DES, Metze, K Teixeira, MAB, Tostes JR, Lopes ER 1974. Encefalopatia chagásica em immunodeprimido por tratamento quimioterápico em portador de leucose crônica: apresentação de caso com necrópsia. Rev Soc Bras Med Trop 24 (Supl. I): 33.

Alvar J 1994. Leishmaniasis and AIDS co-infection: the Spanish example. Parasitol Today 10: 160-163.

Alvar J, Canavate C, Gutierrez-Solar B, Jimenez M, Laguna F, Lopez-Velez R, Molina R, Moreno J 1997. Leishmania and human immunonodeficiency virus confection: the first 10 years. Clin Microbiol Rev 10: 298-319.

Amato Neto V 1970. Aspectos dermatológicos da toxoplasmose. Rev Soc Bras Med Trop 5: 345-348.

Amato Neto V, Doles J, Rassi A, Borges AP, Rezende JM, Gomes COM 1968. Relato de novos casos de transmissão da doença de Chagas por transfusão de sangue. Rev Inst Med Trop São Paulo 10: 46-51.

Ambroise-Thomas P, Pelloux A 1993. Toxoplasmosis - congenital and in immunocompromised patients: a parallel. Parasitol Today 9: 61-63.

Amendoeira MRR 1995. Mecanismos de transmissão da toxoplasmose. Anais Acad Nac Med 155: 224-225.

Anonymous 1996. Pautas para la prevención de infecciones oportunistas en personas com VIH o Sida em America Latina Yel Caribe. Bol Oficina Sanit Panam 121: 377-403.

Araujo FG 1991. Depletion of L3T4(CD4) T lymphocytes prevents development of resistence to Toxoplasma gondii in mice. Infect Immun 45: 122-126.

Araujo FG, Remington JS 1980. Antigenemia in recently acquired acute toxoplasmosis. J Infect Dis 141: 144-150.

Bertoli F, Espino M, Arosemena JR, Fishback JL, Frenkel JK 1995. A spectrum in the pathology of toxoplasmosis in patients with acquired immunodeficiency syndrome. Arch Pathol Laborat Med 119: 214-224.

Bocchi EA, Bellotti G, Uip L, Kalil J, Higushi ML, Fiorelli A, Stolf N, Janete A, Pillegi F 1993. Long term follow-up after heart transplantation in Chagas disease. Transplantation 25: 1329-1330.

Bonacini M 1992. Hepatobiliary complications in patients with human immunodeficiency virus infection. Am J Med 92: 404-411.

Borges AS, Ferreira MS, Nishioka AS, Silvestre MTA, Silva AM, Rocha A 1997. Agreement between premortem and postmortem diagnoses in patients with acquired immunodeficiency syndrome observed at a Brazilian Teaching Hospital. Rev Inst Med Trop SP 39: 217-221.

Borges AS, Figueiredo JFC 2000a. Pesquisa de anticorpos de classe IgG, IgM e IgA, anti-T. gondii, no soro, líquor e saliva de pacientes com síndrome da imunodeficiência adquirida e neurotoxoplasmose. Rev Soc Brasil Med Trop 33 (S-1): 353.

Borges AS, Figueiredo JFC 2000b. Determinação da produção de anticorpos anti- $T$. gondii a nível de sistema nervoso central como subsídio para o diagnóstico da neurotoxoplasmose em pacientes com síndrome da imunodeficiência adquirida. Rev Soc Brasil Med Trop 33 (S-1): 354.

Borges AS, Machado, Ferreira MS, Figueiredo JFC, Silva GF, Cimerman S, Bacha H, Teixeira MCL 1999. Concomitância de leishmanioses e infecção pelos vírus da imunodeficiência humana (HIV): estudo de quatro casos. Rev Soc Bras Med Trop 32: 713-719.

Brenner Z, Chiari E 1971. The effects of some immunosupressive agents in experimental chronic Chagas' disease. Trans $R$ Soc Trop Med Hyg 65: 729-636.

Cantarovich F, Vazquez M, Duro Garcia W, Abbud Filho M, Herrera C, Villegas Hernandez A 1992. Special Infections in organ transplantation in South América. Transplantation 24: 1902-1908.

Cardell RL, Addiss DG 1994. Cryptosporidiosis in child care settings: a review of the literature and recomendations for prevention and control. Pediat Infect Dis J 13: 310-317.

Carey RM, Kimball AC, Armstrong D, Lieberman PH 1973. Toxoplasmosis. Clinical experiences in a cancer hospital. Am J Med 54: 30-38.

Cello JP, Grendell JH, Basuk P 1991. Effect of octreotide on refractory AIDS associated diarrhea - a prospective multicenter clinical trial. Ann Intern Med 115: 705-710.

Cesbron-Delauw MF 1994. Dense-granule organelles of Toxoplasma gondii: their role in the host-parasite relationship. Parasitol Today 10: 296.

Chocair PR, Sabbaga E, Amato Neto V, Shiroma M, Góes GM 1981. Transplante de rim: nova modalidade de transmissão da doença de Chagas. Rev Inst Med Trop São Paulo 18: 43-45.

Clezy K, Gold J, Blaze J, Jones P 1991. Paramomycin for the treatment of cryptosporidial diarrhea in AIDS patients. AIDS 5: 1146-1147.

Cohn JA, McMeeking A, Cohen W, Jacobs J, Holtzman RS 1989. Evaluation of the policy of empiric treatment of suspected toxoplasma encephalitis in patients with the acquired immunodeficiency syndrome. Am J Med 86: 521-527.

Conley FK, Jenkins KA 1981. Immunohistological study of the anatomic relationship of toxoplasma antigens to the 
inflamatory response in the brains of mice chronically infected with Toxoplasma gondii. Infect Immun 31: 11841192.

Corona S, Amanales C, Avaria MLA, Colin E, Donoso S, Advis P, Apt W 1988. Granuloma chagásico del cerebro en um paciente com leucemia linfoblástica. Rev Med Chile 116: 676-80.

Costa-Cruz JM, Ferreira MS 1996. Intestinal parasites in AIDS and + HIV patients in Uberlândia, Minas Gerais, Brazil. Mem Inst Oswaldo Cruz, 91: 685-686.

Coura JR, Galvão Castro B, Grimaldi G 1987. Disseminated american cutaneous leishmaniasis in a patient with AIDS. Mem Inst Oswaldo Cruz 82: 581-582.

Dannemann BR, Israelski DM, Leoung GS, McGraw T, Mills J, Remington JS 1991. Toxoplasma serology, parasitemia and antigenemia in patients at risk for toxoplasmic encephalitis. AIDS 5: 1363-1365.

Danneman BR, McCutchan JA, Israelski DM, Antoniskis D, Leport C, Luft B, Nussbaujm J, Clumeck N, Morlat P, Chiu J, Vildé JL, Orellana M, Feigal D, Bartok A, Heseltin P, Leedom J, Remington J 1992. Treatment of toxoplasmic encephalitis in patients with AIDS: a randomized trial comparing pyrimethamine plus clindamycin to pyrimethamine plus sulfonamides. Ann Int Med 116: 33-43.

Darcy F, Santoro F 1994. Toxoplasmosis. In F Kierszenbaum, Parasitic Infect Imm System, Academic Press, Inc., New York, P. 163-201.

Darcy F, Foudrinier F, Mougeot G, Decoster A, Caron A, MarxChemla C, Capron A, Pinon JM 1991. Diagnostic value of specific IgA antibodies in AIDS patients with Toxoplasma infection: a bicentric evaluation. Immunol Let 30: 345-348.

Davidson RN, Russo R 1994. Relapse of visceral leishmaniasis in patients who were coinfected with human immnodeficiency virus and who received treatment with liposomal amphotericin B. Clin Infect Dis 16: 397-395.

De Artega J, Massari PV, Galli B, Garzon Maceda F, Zlocowsky JC 1992. Renal transplantation and Chagas' disease. Transplantation 24: 1900-1901.

De Gorgolas M, Castrill JM. Fernandez Guereiro ML 1993. Visceral leishmaniasis in patients with AIDS: report of three cases treated with pentavalent antimony and interferon. Clin Infect Dis 17: 56-58.

Dedet JP, Lambert M, Pratlong F 1995. Leishmanioses et infection par le virus de immunodeficience humaine. Presse Medicale 24: 1036-1040.

Derouin F, Mazeron MC, Garin YJD 1997. Comparative study of tissue culture and mouse inoculation methods for demonstration of Toxoplasma gondii. J Clin Microbiol 25: 15971600.

Dupouy-Camet J, Souza SL, Maslo C, Paugam A, Saimot AG, Benarous R, Tourte-Schaefer C, Derouin F 1993. Detection of Toxoplasma gondii in venous blood from AIDS patients by polymerase chain reaction. J Clin Microb 31: 1866-1869.

Eisemberg JNS, Priest JW, Lammie PJ, Colford JM 2001. The serologic response to Cryptospiridium in HIV-infected persons: implications for epidemiologia research. Emerging Infect Dis 7: 1004-1009.

Fachado A, Fonte L, Alberti E, Hadad P, Fonseca L, Machin R, Finlay C 1994. Usefulness of the detection of Toxoplasma gondii antigens in AIDS patients. Rev Inst Med Trop São Paulo 36: 525-529.

Fauci AS 1984. Immunologic abnormalities in the acquired immunodeficiency syndrome. Clin Res 32: 491-499.

Fayer R Ungar BLP 1986. Cryptosporidium spp. and cryptospridiosis. Microbiol Rev 50: 458-483.

Feldman HÁ 1968. Toxoplasmosis. N Eng J Med 279: 13701375.
Felgenhauer K 1982. Differentiation of the humoral immune response in inflammatory disease of the central nervous system. J Neurol 228: 223-237.

Fernandez Guerrero ML, Aguado JM, Buzin L, Barros C, Montalban C, Martin T, Souza E 1987. Visceral leishmaniasis in immnocompromised hosts. Am J Med 83: 1098-1102.

Ferreira MS 1999. Chagas disease and immunossupression. Mem Inst Oswaldo Cruz 94: 325-327.

Ferreira MS, Nishioka AS, Rocha A, Silva AM, Ferreira RG, Olivier W, Tostes Jr S 1991. Acute fatal Trypanosoma cruzi meningoencefalitis in a hemophiliac patient. Am J Trop Med Hyg 45: 723-727.

Ferreira MS, Nishioka SA, Silvestre MT, Borges AS, Nunes Araújo FR, Rocha A 1997. Reactivation of Chagas disease in patients with AIDS: review of the literature. Clin Infect Dis 25: 1397-1400.

Fichtenbanm CJ, Ritchie DJ, Powderly WG 1993. Use of paramomycin for treatment of cryptosporidiosis in patients with AIDS. Clin Infect Dis 16: 298-300.

Figueiredo, JFC, Martinez R, Costa JC, Moysés Neto M, Suaid HJ Ferraz AS 1990. Transmission of Chagas' disease through renal transplantation: report a case. Trans $R$ Soc Trop Med Hyg 84: 61-62.

Figueiredo JFC, Neto MM, Gomes VA, Suaid H, Ferraz AS, Martins ACP, Fiorillo AM 1983. Antibody titers to Toxoplasma gondii in renal transplant patients. Braz J Med Biol Res 16: 235-239.

Flanigan T, Whalen C, Turner J 1992. Cryptosporidiosis infection and CD4 counts. Ann Intern Med 116: 840-842.

França LCM, Fleury R N, Ramos Jr HÁ, Lemos S, Melaragno Filho R, Pasternak J 1969. Moléstia de Chagas crônica associada à leucemia linfática: ocorrência de encefalite aguda como alteração do estado imunitário. Arq Neuropsiquiatr (São Paulo) 27: 59-66.

Frenkel JC, Nelson BM, Arias-Stella J 1975. Immunossupression and toxoplasmic encephalitis. Clinical and experimental aspects. Hum Pathol 6: 97-111.

Frenkel JK 1957. Effects of cortisone, total body irradiation and nitrogen mustard on chronic latent toxoplasmosis. Am J Pathol 33: 618.

Frenkel JK 1973. Toxoplasma in and around us. Bio Sci 23: 343-352.

Frenkel JK 1988. Pathophysiology of toxoplasmosis. Parasitol Today 4: 273-278.

Fuccillo EA, Madden EE, Tzan N, Sever JL 1987. Difficulties associated with serological diagnosis of Toxoplasma gondii infections. Diag Clin Imm 5: 8-13.

Garly M, Eskild P, Petersen C, Lundgren JD, Gerstoft J 1997. Toxoplasmosis in Danish AIDS patients. Scand J Infect Dis 29: 597-600.

Gazzinelli RT, Eltowm I, Wynn TA, Sher A 1993. Acute cerebral toxoplasmosis is induzed by "in vivo" neutralization of TNF- $\alpha$ and correlates with the down-regulated expression of inducible nitric oxide synthase and other markers of macrophage activation. J Immunol 151: 3672-3681.

Gazzinelli RT, Hakim FT, Hieny S, Shearer GM, Sher A 1991. Synergistic role of CD4+ and CD8+ T lymphocytes in IFN- $\gamma$ production and protective immunity induced by an attenuated Toxoplasma gondii vaccine. J Immunol 146: 286292.

Gazzinelli RT, Wysocka M, Hayashi S, Denkers EY, Hieny S, Caspar P, Trinchieri G, Sher A 1994. Parasite-induced IL12 stimulates early INF- $\gamma$ synthesis and resistance during acute infection with Toxoplasma gondii. J Immunol 153: 2533-2542.

Gazzinelli RT, Xu Y, Hieny S, Cheever A, Sher A 1992. Simultaneous depletion of CD4+ and CD8+ T lymphocytes is 
required to reactivate chronic infection with Toxoplasma gondii. J Immunol 149: 175-180.

Geiseler PJ, Ito JL, Tegtmeir BR, Kerndt PR, Krance R 1987. Fulminant Chagas disease in bone morrow transplantation (BMT). In Program and Abstracts of the 27 th Interscience Conference on Antimicrobial Agents and Chemotherapy, New York, Washington DC, p. 169.

Gilks CF 1993. The clinical challenge of the HIV epidemic in the developing world. Lancet 342: 1037-1039.

Gluckstein D, Ciferri F, Ruskin J 1992. Chagas' disease another cause of cerebral mass in the acquired immunodeficiency syndrome. Am J Med 92: 429-432.

Goldstein ST, Jurane KDD, Ravenholt O 1996. Cryptosporidiosis: an outbreak associated with drinking water despite state-of-art water treatment. Ann Intern Med 124: 459-468.

Gradoni L, Scalone A, Gramiccia M, Troiani M 1996. Epidemiological surveillance of leishmaniasis in HIV-1 infected individuals in Italy. AIDS 10: 785-791.

Grant IH, Gold JWM, Rosenblum M, Niedzwiecki D, Armstrong D 1990. Toxoplasma gondii serology in HIVinfected patients: the development of central nervous system toxoplasmosis in AIDS. AIDS 4: 519-521.

Grant IH, Gold JWM, Wittner M, Tamowitz HB, Nathan C, Mayer K, Reich L, Wollner N, Steinherz L, Ghavini F, O' Reilly RJ, Armstrong D 1989. Transfusion associted acute Chagas' disease acquired in the United States. Ann Int Med 111: 849-851.

Gray GF, Gherarde R, Wingate E, Wingate J, Fenelon G, Gaston A, Sobel A, Poiner J 1989. Diffuse encephalic cerebral toxoplasmosis in AIDS: report of 4 cases. J Neurol 236: 273 277.

Griffiths JK 1998. Human cryptosporidiosis: epidemiology, transmission, clinical disease, treatment and diagnosis. $A d v$ Parasitol 40: 37-85.

Gross U, Roos T, Appoldt D, Heesemann J 1992. Improved serological diagnosis of Toxoplasma gondii infection by detection of immunoglobulin A ( $\operatorname{Ig} \mathrm{A})$ and $\operatorname{IgM}$ antibodies against P30 by using immunoblot technique. J Clin Microbiol 30: 1436-1441.

Guerrant RL 1997. Cryptosporidiosis: an emerging, highly infectios threat. Emerging Infect Dis 3: 51-55.

Hafid J, Tranmanh SR, Raberin H, Akono ZY, Pozzetto B, Jana M 1995. Detection of circulating antigens of Toxoplasma gondii in human infection. Am J Trop Med Hyg 52: 336339.

Hakes TB, Armstrong D 1983. Toxoplasmosis. Problems in diagnosis and treatment. Cancer 52: 1535-1540.

Herwaldt BL, Juranok DD 1993. Laboratory acquired malaria, leishmaniasis, trypanosomiasis and toxoplasmosis. Am Soc Trop Hyg 48: 313-323.

Hewitt RG, Yiannoutsos CT, Higgs ES, Carey JT, Geiseler PJ, Soave R, Rosemberg R, Vazquez GJ, Wheat LJ, Fass RJ, Antoninevic Z, Walawander AL, Flanigan TP, Bender JF 2000. Paramomycin: no more effective than placebo for tratment of cryptosporidiosis in patients with advanced human immunodeficiency virus infection. Clin Infect Dis 31: 1084-1092.

Hofflin JM, Remington JS 1985. Tissue culture isolation of Toxoplasma from blood of a patient with AIDS. Arch Int Med 145: 925-926.

Hoxie NJ, Davis JP, Vergeront JM, Nashold R, Blair KA 1997. Cryptosporidiosis-associated mortality following a massive waterborne outbreak in Milwaukee, Wisconsin. Am J Publ Health 87: 2032-2035.

Huskinson J, Thulliez P, Remington JS 1990. Toxoplasma antigens recognized by human immunoglobulin A antibodies. $J$
Clin Microb 28: 2632-2636.

Israelski DM, Remington JS 1993. Toxoplasmosis in the nonAIDS immunocompromised host. In J Remington, M Swartz (eds), Current Clinical Topics in Infectious Diseases, Vol. 13, Blacwell Scientific, London, p. 322-356.

Jautzke G, Sell M, Thal Mann V, Janitschke K, Gottscha LK, Schurmann D, Ruf B 1993. Extracerebral toxoplasmosis in AIDS: histological and immunohistological findings based on 80 autopsy cases. Pathol Res Pract 189: 428-436.

Johnson WD 1981. Chronological development of cellular immunity in human toxoplasmosis. Infect Immun 33: 948949.

Jost L, Turin M, E Tchegoyen F, Leiguarda R, Torcuato A, Iotti R 1977. Meningoencefalite chagasica em paciente com tratamento inmunosupresor por transplante renal. Rev Neurol Arg 3: 425-428.

Karp CL, Neva FA 1999. Tropical infections diaseases in human imumunodeficient virus-infected pacients. Clin Infect Dis 28: 947-965.

Katlama C, De Witt S, O’Doherty E 1996. Pyrimethamineclindamycin vs. Pyrimethamine-sulfadiazine as acute and long-term therapy for toxoplamic encephalitis in patients with AIDS. Clin Infect Dis 22: 268.

Kaufmann SHE 1995. Immunity to intracellular microbial pathogens. Immunol Today 16: 338-342.

Khalifa KS, Roth A, Roth B, Arasteh KN, Janitschke K 1994. Value of PCR for evaluating occurrence of parasitemia in immunocompromised patients with cerebral and extracerebral toxoplasmosis. J Clin Microbiol 32: 2813-2819.

Kirchoff LV 1993 American trypanosomiasis (Chagas' disease) - A tropical disease now in the United States. N Engl J Med 329: 639-644.

Kohl S, Pickering L K, Frankel LS, Yalger RG 1982. Reactivation of Chagas disease during therapy of acute lymphocytic leukemia. Cancer 50: 827-828.

Kovacs JÁ 1992. Efficacy of atovaquone in treatment of toxoplasmosis in patients with AIDS. Lancet 340: 637.

Krick JA, Remington JS 1978. Toxoplasmosis in adult - An overview. N Engl J Med 298: 550-553.

La Rosa R, Pineda JA, Delgado J, Macias J, Morillas F, Martin Sanchez J, Leal M, Sanchez Quijano A, Lissen E 2001. Influence of highly active antiretroviral therapy on the outcome of subclinical visceral leishmaniasis in human immunodeficiency virus infected patients. Clin Infect Dis 32: 633-635.

Letillois MF, Laigle V, Santoro F, Micoud M, Chumpitazi BFF 1995. Toxoplasma gondii surface antigen-1 in sera of HIVinfected patients as an indicator of reactivated toxoplasmosis. Eur J Clin Microb Infect Dis 14: 899-903.

Lite DB, Mendonça IL, Luz FCO, Abreu EAS, Mello GWS, Farias TJC, Ferreira AFB, Willington MA, Costa CHN 2001. QBC@ for the diagnosis of human and canine American visceral leishmaniasis: preliminary data. Rev Soc Bras Med Trop 34: 577-581.

Lopez-Blanco AO, Cavalli NH, Jasovich A, Gotlieb D, Gonzalez Cappa S 1992. Chagas' disease and kidney transplantation - follow-up of nine patentes for 11 years Transplantation 24: 3089-3090.

Lopez-Velez R, Perez Molina JA, Guerrero A, Baquero F, Villarrubia J, Escribano L, Bellas C, Perez-Carrol F, Alvar J 1998. Clinicoepidemiologic caracteristics, prognostic factors and survival analysis of patients coinfected with human immunodeficiency virus and Leishmania in an area of Madrid, Spain. Am J Trop Med Hyg 58: 436-443.

Luders C, Caetano MA, Ianhez LE, Fonseca JA, Sabbaga E 1992. Renal transplantation in patients with Chagas' disease: a long-terrn follow-up. Transplantation 24: 1878- 
1879.

Luft BJ, Remington JS 1988. Toxoplasmosis encephalitis. $J$ Infect Dis 157: 1-6.

Luft BJ, Brooks RG, Conley FK, McCabe RE, Remington JS 1984. Toxoplasmic encephalitis in patients with acquired immunodeficiency syndrome. JAMA 252: 913-917.

Luft BJ, Conley F, Remington JS, Laverdiere M, Levine JF, Strandberg DA, Wagner KF, Craven PC, File T, Tice N, Carpentier FM 1983. Outbreak of central-nervous-system toxoplasmosis in western Europe and North America. $N$ Eng J Med 1: 781-783.

Luft BJ, Hafner R, Korzun AH, Leport C, Antoniskis D, Bosler E, Bourland D, Uttamchandani R, Fuhrer J, Jacobson J, Morlat P, Vilde JL, Remington JS 1993. Toxoplasmic encephalitis in patients with the acquired immunodeficiency syndrome. N Eng J Med 329: 995-1000.

Machado ES, Braga MP, Da Cruz AM, Coutinho SG, Vieira ARM, Rutowitsch MS, Cussi-Maya T, Grimaldi G, Menezes JÁ 1992. Disseminated american mucocutaneaus leishmaniasis caused by Leishmania braziliensis braziliensis in a patient with AIDS: a case report. Mem Inst Oswaldo Cruz 87: 487-492.

Manabe YC, Clark DP, Moore RD, Lumadue JÁ, Dahlman HR, Belitsos PC 1998. Cryptosporidiosis in patientes with AIDS: correlates of disease and survival. Clin Infect Dis 27: 536-542.

McCabe RE, Remington JS, Araujo FG 1985. "In vivo" and "in vitro" effects of cyclosporin A on Trypamosoma cruzi. Am J Trop Med Hyg 34: 861-865.

Mechert PMC, Chambo JG, Langrens RP 1988. Modification of the pattern of infection and evolution of cardyopatology in experimental Chagas' disease after treatment with immunosupressive trypanocidal drugs. Medicina (Buenos Aires) 48: 7-11.

Medrano FJ, Hernandez Quero J, Jimenez E, Pineda J, Rivero A, Sanchez Quijano A, Lissen E 1993. Visceral leishmaniasis in HIV-1 infected individuals: a common opportunistic infection in Spain? AIDS 6: 1499-1503.

Monteverde DA, Taratuto AL, Lucatelli N 1976. Meningoencefalite chagásica aguda em pacientes imunossuprimidos. Rev Neurol Arg 2: 260- 266.

Moore AC, Herwauldt BL, Craun GF 1993. Surveillance for waterborne disease outbreaks, United States, 1991-1992. MMWR 42 (Suppl. 55-5): 1-22.

Moos DM, Bennett SN, Arrowood MJ, Wahlquist SP, Lammie PJ 1998. Enzyme-linked immunoelectrotransfer blot analysis of a cryptosporidiosis outbreak on a United States Coast Guard cutter. Am J Trop Med Hyg 58: 110-118.

Morgado MG, Barcellos C, Pina MF, Bastos FI 2000. Human immunodeficiency virus/acquired immnodeficiency syndrome and tropical diseases: a Brazilian perspective. Mem Inst Oswaldo Cruz 95: 145-151.

Morrow RH, Colebunders RL, Chin V 1989. Interactions of HIV infection with endemic tropical diseases. AIDS 3: 579587.

Moura H, Fernandes O, Viola JPB 1989. Enteric parasites and HIV infection: ocurrence in AIDS patients in Rio de Janeiro, Brazil. Mem Inst Oswaldo Cruz 84: 527-533.

Müller F, Moskophidis M 1983. Estimation of the local production of antibodies to Treponema pallidum in the central nervous system of patients with neurosyphils. Brit J Vener Dis 59: 80-84.

Navin TR, Roberto RR, Juranela DD, Lempakarnjanrat K, Mortenson EW, Clower JR, Yercott JR, Taclindo C, Steurer F, Allain D 1985. Human and sylvatic Trypanosoma cruzi infection in California. Am J Publ Health 75: 366-369.

Nickerson P, Orr P, Schroeder ML, Sekla L, Johnston JB 1989.
Transfusion associated Trypanosoma cruzi infection in a non-endemic area. Ann Intern Med 111: 851-853.

Nishioka SA, Ferreira MS, Rocha A, Borges AS 1993. Reactivation of Chagas' disease successfully treated with benznidazole in a patients with acquired immunodeficiency syndrome. Mem Inst Oswaldo Cruz 88: 493-496.

Oddo' D, Casanova M, Acuña G, Ballesteros J, Morales B 1992. Acute Chagas' disease (typanosomiasis americana) in acquired immunodeficiency: report two cases. Hum Pathol 23: 42-44.

Orefice G, Carrieri PB, De Marinis T, Troisi E, Farace A, Noice S, Buscaino GA 1990. Use of the intrathecal synthesis of antitoxoplasma antibodies in the diagnostic assessment and in the follow-up of AIDS patients with cerebral toxoplasmosis. Acta Neurol 12: 79-81.

Pan American Health Organization 1990. Health conditions in the Americas, Scientific Publication 524, Vol. 1, Washington, DC, p. 160.

Parker SJ, Roberts CW, Alexander J 1991. CD8+ T cells are the major lymphocyte subpopulation envolved in the protective immune response to Toxoplasma gondii in mice. Clin Exp Immunol 84: 207-212.

Parmley SF, Goebel FD, Remington JS 1992. Detection of Toxoplasma gondii in cerebrospinal fluid from AIDS patients by polymerase chain reaction. J Clin Microbiol 30: 30003002.

Pedersen C, Danner S, Lazzarin A 1996. Incidence of cryptosporidiosis among European AIDS patients. Genitourin Med 72: 128-131.

Piarroux R, Gambarelli F, Dumon H; Fontes M, Fontes M, Dunan S, Mary C, Toga B, Quilici N 1994. Comparison of PCR with direct examination of bone marrow, myeloculture and serology for diagnosis of visceral leishmaniasis in immunocompromised patients. J Clin Microbiol 33: 746749.

Pinon JM, Thoannes H, Pouletty PH, Poirriez H, Damiens J, Pelletier P 1986. Detection of IgA specific for toxoplasmosis in serum and cerebrospinal fluid using a non-enzymatic IgA-capture assay. Diag Immunol 4: 223-227.

Pizzi T, De Croizet VA, Smoky G, Diaz M 1982. Enfermedad de Chagas en um paciente com transplante renal y tratamento imunosupresor. Rev Med Chile 110: 1207-211.

Porter SB, Sande MA 1992. Toxoplasmosis of the central nervous system in the acquired immunodeficiency syndrome. New Eng J Med 327: 1643-1648.

Potasman I, Resnick L, Luft BJ, Remington J1988. Intrathecal production of antibodies against Toxoplasma gondii in patients with toxoplasmic encephalitis and the acquired immunodeficiency syndrome (AIDS). Ann Inter Med 108: 4951.

Pozio E, Rezza G, Boschini A, Boschini A, Pezzotti P, Tamburrini A, Rossi P 1997. Clinical cryptosporidiosis and human immunodeficiency virus (HIV) - induced immunossupression: findings from a longitudinal study of HIV - positive and HIV-negative former infection drug users. J Infect Dis 176: 969-975.

Queiróz AC 1973. Tumorlike lesion of the brain caused by Trypanosoma cruzi. Am J Trop Med Hyg 22: 473-476.

Rabelo A, Andrade MO, Disch J 1998. Coinfecção Leishmania/HIV. Rev Soc Bras Med Trop 31: 81-91.

Reiber H 1980. The discrimination between different bloodCSF barrier dysfunctions and inflammatory reactions of the CNS by a recent evaluation graph for the protein profile of cerebrospinal fluid. J Neurol 224: 89-99.

Ribera E, Ocana I, Otero J, Cortes E, Gasser I, Pahissa A 1996. Prophylaxis of visceral leishmaniasis in human immunodeficiency virus infected patients. Am J Med 100: 496-501. 
Richardson AJ, Frankenberg RA, Buck AC 1991. An outbreak of waterborne cryptosporidiosis in Swinton and Oxfordshire. Epidemiol Infect 107: 485-495.

Rivero I, Moravenik M, Morales J, Gomez M, De Rosas JM 1974. Chagas disease - another hazard in acute leukemia. N Engl J Med 290: 285.

Rocha A, Ferreira MS, Nishioka SA, Silva M, Burgarelli MKN, Silva AM, Moura LP, Ugrinovich R, Raffin C 1993. Trypanosoma cruzi meningoencephalitis in a patient with acquired immunodeficiency syndrome. Rev Inst Med Trop São Paulo 35: 205-208

Rocha, A, Menezes ACO, Silva AM, Ferreira MS, Nishioka AS, Burgarelli MKN, Almeida E, Turcato JR G, Metz K, Lopes ER 1994. Pathology of patients with Chagas disease and acquired immunodeficiency syndrome. Rev Inst Med Trop São Paulo 35: 205-208.

Rosenthal E, Marty P, Faraut-Gambarelli F 1999. Epidemiologie de la coinfection Leishmania/VIH dans le sud de la France entre 1986 et 1997. Rev Med Interne 20: 73.

Rosenthal E, Marty P, Guidice P, Pradier P, Ceppi C, Gastant JA, Fichoux Y, Cassuto JP 2000. HIV and Leishmania coinfection: a review of 91 cases with focus on atypical locations of Leishmania. Clin Infect Dis 3: 1093-1095.

Rosenthal E, Marty P, Poizot Martin I, Reynnes J, Pratlong F, Lafeuilla de A, Jaubert D, Boulat O, Dereure J, Gambarelli F, Gastant JÁ, Dujardin P, Dellamonica P, Cassuto JP 1995. Visceral leishmaniases and HIV-1 coinfection in southern France. Trans $R$ Soc Trop Med Hyg 89: 159-162.

Ruskin J, Remington JS 1976. Toxoplasmosis in the compromised host. Ann Int Med 84: 193-199.

Saba J, MorlaT P, Raffi F 1993. Pyrimetamine plus azithromycin for treatment of acute toxoplasmic encephalitis in patients with AIDS. Eur J Clin Microbiol Infect Dis 12: 853.

Sartori AMC, Shikanai Yasuda MA, Amato NetoV, Lopes MH 1998. Follow up of 18 patients with human immunodeficient virus infection and chronic Chagas' disease, with reactivation of Chagas' disease causing cardiac disease in three patients. Clin Infect Dis 26: 177-179.

Sims TA, Talbot IC 1989. An electron microscope and immunohistochemical study of intracellular location of Toxoplasma gondii cysts within the brains of mice with congenital toxoplasmosis. Braz J Exper Pathol 70: 317-325.

Sinagra A, Riarte A, Lauricella M, Segurra EL, 1993. Reactiva- tion of experimental chronic T. cruzi infection after immunosupressive treatment by cyclosporive $\mathrm{A}$ and betanetasone. Transplantation 55: 1431-1434.

Sorvillo F, Beall G, Turner PA, Beer VL, Kovacs AA, Kraus P 1998. Seasonality and factors associated with cryptosporidiosis among individuals with HIV infection. Epidemol Infect 121: 197-204.

Stolf NAG, Higushi L, Bochi E, Bellotti G, Auler JOC, Uip D, Amato Neto V, Pillegi F, Jatene A D 1987. Heart transplantation in patents with Chagas disease cardiomyopathy. J Heart Transpl 6: 307-312.

Tirard V, Niel G, Rosenheim M, Katlama C, Ciceron L, Ogunkolade W, Danis M, Genrilini M 1991. Diagnosis of toxoplasmosis in patients with AIDS by isolation of the parasite from the blood. New Eng J Med 324: 634.

Tschirhart D, Klatt EC 1988. Disseminated toxoplasmosis in the acquired immnunodeficiency syndrome. Arc Path Labor Med 112: 1237-1241.

Van Thiel PH 1966. The parasitology of toxoplasmosis in the central nervous system. Psych Neurol Neuroch 60: 7-13.

Wanderley DMV, Camargo LMA, Carvalho ME 1988. Doença de Chagas: registro de caso agudo transfusional. Rev Inst Med Trop São Paulo 30: 437-440.

Wanke C, Tuazon CU, Kovacs A, Dona T, Davis D, Barton N, Katz D, Lunde M, Levy C, Conleu FK, Lane HC, Fauci AS, Masur H 1987. Toxoplasma encephalitis in patients with acquired immune deficiency syndrome: diagnosis and response to therapy. Am J Trop Med Hyg 36: 509-516.

Weiss LM, Udem AS, Tanowitz H, Wittner M 1988. Western Blot analysis of the antibody response of patients with AIDS and Toxoplasma encephalitis: antigenic diversity among Toxoplasma strains. J Infect Dis 157: 7-13.

Wong B, Gold JWM, Brown AE, Lange M, Fried R, Grieco M, Mildvan D, Giron J, Tapper ML, Lerner CW, Armstrong D 1984. Central-nervous-system toxoplasmosis in homossexual men and parenteral drug abusers. Ann Int Med 100: 36-42.

Young LS 1981. Infection in the compromised host. Hosp Pract 16: 73-84.

Zangerle R, Allerberger F, Pohl P, Fritsch P, Dierich MP 1991. High risk of developing toxoplasmic encephalitis in AIDS patients seropositive to Toxoplasma gondii. Med Microb Immunol 180: 59-66. 